\title{
LOCAL APPROACHES TO ARCHITECTURAL APPROACH FOR SUSTAINABLE URBAN DEVELOPMENT (CASE STUDY OF KERMAN CITY)
}

\author{
Nazila Kabiri \\ Lamei Gorgani Institute of Higher Education
}

\begin{abstract}
Urban rapid development has influenced human life in various decades of contemporary social, economic, cultural, political, environmental and other dimensions. Sustainable development is debatable at various levels and is expressed in different scales from textures and neighborhoods to the sustainable development of metropolises and sustainable development worldwide. The point to be considered here is that our ancestors, centuries ago, with a close look at the canvas, the region and its present conditions, provide the best and cleanest ways to interact with nature and provide a suitable environment for addressing various aspects of private and social life, sustainable and The dynamic has been provided in the areas mentioned. Certainly, the study of these traditional approaches can be used as a way to realize sustainability criteria in today's architecture and urbanization. In this paper, firstly, the concept of sustainable development is expressed in terms of its common ground with native architecture. Then, the adaptive analytical method of the native architecture of Kerman and its traditional architectural features have been adapted to the sustainability criteria and principles of sustainable global development. The purpose of this adaptation is to understand the extent to which Kerman's native architecture is coordinated as a local approach with an architectural approach to sustainable urban development.
\end{abstract}

Keywords: architectural approach, urban, development

\section{INTRODUCTION}

The insustainability of urban development is the most important challenge of the third millennium, the metropolis of large cities today is now more than ever looking for foundations for sustainable development. To this end, the Sustainable Development Commission was set up following the Highland Summit (1992, Rio de Janeiro), one of its goals being to develop sustainable development indicators for measuring, monitoring and improving sustainable development. The introduction and use of these indices is necessary in our country. Less attention has been paid to it. Urban rapid development has affected various aspects of social, economic, cultural, political, environmental, and even human life in recent decades. Therefore, the emergence of sustainable development, as the main slogan of the third millennium, is due to the effects of cities on the biosphere scope and different dimensions of human life. Undoubtedly, the debate about sustainability and sustainable development without meaning for cities and urbanization would be meaningless. Cities are considered as the main cause of insustainability in the world, and, in fact, urban sustainability and global sustainability are both common concepts. Accordingly, considering the inherent complexity of cities and their different dimensions, the identification of key factors for achieving urban sustainability is necessary.

Rapid urbanization along with major changes in the urban style and way of life influenced by the capitalist system and the entry of cars and other new technologies has led to the emergence of numerous urbanization and urban problems in all aspects of the social, economic, environmental and in particular the physical form of cities. One of the places that has been heavily influenced by these developments is the urban neighborhoods system, both in old cities and in new cities, which has led to the collapse and breakdown of the interactions and lifestyles of these neighborhoods. Therefore, the obstacles to creating sustainable architecture can be solved by considering sustainable architecture as a process and paying attention to the native fields of its formation. (Zamankhani, 2018) In most cities of Iran, especially in desert areas with rich architecture, including the city of Kerman, newly constructed collections and neighborhoods lack the values and ideas by which these cities are renowned for their architectural and cultural richness. In other words, insustainability in newly 
constructed textures is a serious deterrent to the sustainable image of these cities. From this perspective, it is very important to pay attention to the aspects and characteristics that can contribute to the sustainability and unity of these tissues.

\section{DEVELOPMENT}

Development in the broadest definition is the movement based on planning and thinking of the status quo to achieve desired status and goals in short or long term horizons. One of the features of our age is urbanization and increasing urban populations, and consequently the development of small and large cities. Often, the goal is to develop, improve, develop a living standard and achieve ideal conditions. But the realization of this goal depends on many factors. The development of various definitions and concepts has been proposed by the scholars, and although the concept of advancement, growth, development, and expansion has been posed very far in the field of social and economic literature, the term development has become prevalent in the current prevailing concept since World War II. Concepts of Advancement - Transformation - Growth - Progression and Expansion in fact, although a move towards the improvement of the conditions and conditions of a society has been taken into account, it has a relatively limited development in terms of development. This improvement of the current situation will be achieved when it comes to the development, development, and dissemination of all-round, inclusive and contradictory ideas to meet the tangible and intangible needs of this society. Growth in the material and spiritual aspects, from the scale of the neighborhood to the world, and in different economic, cultural, political and other spheres ... Therefore, the notion of concept makes development more effective. These qualities are consistent with the concept of sustainability.

\section{SUSTAINABILITY}

Dehkhoda has given sustainability a durable, lasting and eternal life. In general, sustainability can be defined as what continues in the future. "Using resources in a way that does not harm them and does not end them." In the Webster dictionary, sustainability appeared at first initially as mental imagery. Sustainable development is in fact the creation of a balance between development and the environment. In 1980, for the first time, the name of sustainable development came from the World Conservation Report.

In its report, Natural Resource Conservation Strategy, the organization used this term to describe a situation in which development is not only harmful to nature, but also contributes to it. Sustainability can have four aspects: sustainability in natural resources, political sustainability, social sustainability and economic sustainability. In fact, sustainable development does not focus solely on the occasional environmental aspect, but also on social and economic aspects. Sustainable development is the intersection of society, the economy and the environment. One of the most important international events in the field of sustainable development is the World Summit on Sustainable Development.

At the meeting, agreements were reached on sustained development among participants. Reducing the number of people who do not have access to water by 2015, by half by 2015, minimizing the impact of human and environmental hazards on chemicals will halve the decline in sea stocks and bring marine resources to a sustainable level by 2015 It was the main agreement of the meeting to reduce the decline of natural variation by 2010 , to increase the sustainability of renewable energy use and to plan for a 10-year plan for sustainable development. However, many government officials and environmental activists are now struggling to achieve sustainable development, but some environmentalists do not consider this option sufficient to protect the environment. They believe that the term "sustainable development" is not appropriate in the context of the use of resources and the elimination of resources in the world, and should be used as an alternative to "development sustainability", so that the concept is not conjunct in the minds of new sources to be produced.

At the World Conference on the Environment and Development of the United Nations (1987), sustainable development was defined as a process that meets the current needs without destroying the capabilities of future generations to meet their needs (Tosun, 2006,289-303) In the middle years of the

Submit Date: 09.01.2018, Acceptance Date: 23.02.2018, DOI NO: 10.7456/1080MSE/137 
twentieth century, sustainability went beyond the emphasis on the environment, and came to the fore in other areas such as social and economic. In the last two decades of this century, it has come to the fore in international societies and among official organizations.

Adams mentions sustainability as a green development and green policy, and sees conservation of natural resources as essential to sustaining the human race and future generations as the foundation for sustainable development. (Adams, 199.25-50) The vote of Sustainability and Development aims to reduce unemployment, poverty and poverty. (Roy, 1993, 56) For Hugton, sustainable urban development emphasizes a process in which the city's energy flow in the minimum operating conditions is maximized, and environmental damages are minimized. (Haughton, G, 1977, 192) Hence the sustainability of the effective and efficient use of resources, including nature, human, and technology. So that at the same time, meeting the needs of today's human beings, will also meet the needs of the future.

In other theories, such as the ecological city, sustainability is the creation of dense cities, cheap housing, the promotion of social justice, the creation of city gardens and the support of economic activities with ecological considerations. (Moses Kazemi Mohammadi 2003: 106-104) The mental health theory is essential for citizens' participation in shaping the city, decent access to services and urban sustainability. (Ziari, 1998: 16)

Hence, although it is difficult to provide a precise definition for the sustainability of work. But the two criteria set out below define the concept of sustainability to some extent:

1) Improving the quality of life while taking into account the capacity to withstand the environment.

2) meeting the needs of the present generation without limiting the capabilities and capabilities of future generations to meet their needs. This definition of needs does not have a physiological aspect and its sources include nature, human and technology.

\section{Sustainable Urban Development Areas}

On the other hand, in the 1970s, the rapid growth of development programs, both consciously and unconsciously, along with environmental threats, created social and economic threats. (Borton 2003, 18) In response to these implications, new concepts and trends for sustainable development and its domains were expressed and the concept of sustainable development was important in various areas of human life.

The idea of sustainable urban development is one of the most extensive aspects of developmental studies. Providing a definite definition in this regard is not so simple, but it attempts to explain the meaning of sustainable urban development between concepts-principles-the history of applied studies. The idea of urban development is not related to historical developments, but in this regard the wise development of various sciences and social knowledge is also raised. Attention to developments will increase the volume and quality of existing knowledge about the urban environment, including identification and elimination of air pollution - greenhouse gases - global climate change and so on. Developments in the field The social sciences are also conducted with the help of various research agendas on sustainable development. The above points out that the development of urban development has been influenced by various concepts and issues and has been confronted with sciences such as economic policies and theoretical and empirical knowledge. And sometimes also shaped or changed with historical developments (Nasi A, 1998: 17)

An urban community, along with a sustainable urban environment, requires a sustainable urban economy, sustainable urban living, and other sustainability dimensions, all of which are referred to as intergenerational equity and the principle of social justice and the equality of the next generation and the principle of the future generation. Today, it is believed that the survival of cities lies not in the fight against what is natural, but in reconciliation and coherence with its forces. A sustainable city and sustainable urban landscape is a general system in which all its components, such as individuals, bodies, space, laws, environments and various institutions, culture, etc., remain in a relationship with each other and around themselves (Wheeler, 2017)

\section{Architectural position in sustainable urban development}


In the global move to support the development system, architects, together with other specialists in different disciplines, are looking for new solutions for the satisfactory living and development of human beings. The design of buildings, structures, and neighborhoods has a direct impact on all aspects of the world's environment. These effects extend beyond the sustainability implications of sustainable development, including economic, social, cultural, and so on. (Mahmoodi 2009: 4)

It is also very important that the achievement of a sustainable city and its appearance does not necessarily follow a single and universal structure. But various cities with different cultural, political and economic structures and backgrounds are subject to many general laws governing the sustainability of the systems. In fact, the fields and structures for achieving urban sustainability and urban landscape can never be imported into a urban system like goods. Growth and developmental fields in any urban system have structural, physical, cultural and social features unique to the system itself, and only through the discovery of the mechanisms of these structures can be the way to build sustainable cities and sustainable urban landscape.

A stable architecture mix can not be moved from one place to another as a ready made product. Nevertheless, sustainable urban development has features, principles and criteria as the main policy that can be divided into areas. Most researchers, according to the Brentland Report, have three layers of development, equality and egalitarianism and environmental protection. Biomedicine explores sustainable development in three ecological, environmental, economic and social dimensions. Others, including Sachs, add two spatial and cultural dimensions. Also, some such as Giorgio (1996), Chalers (1995), Kumar (1993), and others who believe in institutional or political sustainability are in a sustainable development. Failure to achieve any of the dimensions will weaken the sustainability and stay away from the shape of sustainable development. (SAS, 1993: 10-2)

Achieving this goal will be achieved by recognizing the characteristics in the context and endowing the parameters of sustainable development. What has increased the significance of localization in recent years is the emergence of the fact that the attraction of the methods and experiences of others, regardless of the differences between societies, cultures and spaces, can not lead to a lasting and durable development in this Communities. Experience has made it clear that many of the traditional techniques and techniques in the field of production, culture and society in native local communities are consistent with the biomass of these societies, which are today indicative of ways to achieve sustainable development.

\section{Cultural sustainability}

Cultural sustainability is defined in terms of the ability to preserve cultural identity and the tolerance of change in adapting to cultural values of peoples. In the context of the concept of sustainability, culture is a cultural asset that includes relationships and values, heritage and location, arts, diversity, and history. The cultural, material and immaterial accumulation is inherited from the predecessors and laid to the posterity. In recent years, it has become clear that the economy alone can not provide a plan for prosperity, in accordance with human dignity, and in order to maintain human dignity, it is necessary to pay attention to the culture of different regions in the implementation of the project. The emphasis on cultural identity means not looking at advanced societies and not learning them in the direction of a cultural transformation, but also maintaining the cultural identity with the ideals of modernization, as these ideals provide the context for development in traditional societies. They bring. In the dimension of cultural sustainability, the culture of human relations is defined with nature and the environment. Individual and social attitudes and beliefs are related to environmental protection, protection of values and institutions (ibid. 17-4)

\section{Economic sustainability}

In general, a sustainable regional economy should always consider the following three principles:

1) An economy that addresses the social and environmental damages of the past and avoids new issues.

2) Economic is a human being, meaning that it can meet the real human needs and maximize economic efficiency with the focus of human attention. 
3) It should be local economy, ie, based on local ownership, local control, local capital and local resources (Bahrain and Afghanistan)

The components that are consistent with the above aims to ensure the achievement of sustainable economies can be summarized as follows: proper use of land and attention to the tolerable capacity of urban land, increased productivity due to the concentration and attention to spaces that are in effect Focus can be more efficient and productive, increasing productivity through multiple uses of space, reducing time and cost of displacement by reducing the gap between related activities.

\section{Environmental sustainability}

Examples of environmental sustainability factors include:

1) Energy Saving to Reduce Non-renewable Resources: A number of environmental considerations that can have an important impact on reducing energy consumption and achieving environmental sustainability. Paying attention to the climatic conditions of the area, paying attention to land factors Cognitive and soil science, the use of indigenous materials and the combination with modern methods of construction, paying attention to the governing relationships between urban functions and activities, and planning and designing properly to reduce the volume of communications between applications, preventing the extraordinary expansion of cities, paying attention to topographic issues Area (same)

2) Reducing environmental pollution and protecting a healthy and sustainable environment: Some of the components considered include the reduction of urban transport, especially transport based on the use of fossil fuels, preventing urban wasteful development that will contaminate environmental resources. Attention to the natural and climatic issues in the location of urban utilities (the same 6040)

\section{Social sustainability}

According to Bramley et al. (2009), social sustainability has two dimensions:

1) Sustainability: Includes pride and belonging to neighborhoods, social interaction between neighbors, safety and security, perceptual quality of the local environment, satisfaction with housing and housing.

2) Equal social rights: Access to services and opportunities, such as essential local services, shops, schools and health centers, recreational opportunities, public transportation, job opportunities and housekeeping (ibid. 41-60)

Damrricher and Clab (2007) believe in space experiments in seven intermittent spaces that sustainability in these spaces results in social sustainability. 1) My body and I, 2) Interior home, 3) Street, 4) Village and foreign border, 5) District, 6) Generation, 7) Earth. (Dumriecher, H \& Kolb, B 2007)

According to the principles of social sustainability, the indicators of sustainable social development in architecture are expressed in three general areas: social interaction, architectural identity, social security. The concept of sustainability varies depending on the circumstances of the time and place of different communities, and therefore the possibility There is no broadening of a particular conception of the concept of sustainability. Although for sustainability analysis, we must consider three dimensions, but sustainability is not a prescriptive prescription for green values, but an advocate of inventory values associated with certain forms of re-production of behaviors.

\section{Native architecture and sustainable development}

Sustainable architecture is in the midst of traditional Iranian buildings. Due to the global energy crisis and the ending of renewable energy sources as well as increased environmental pollution due to the untapped use of fossil fuels, the use of sustainable energy, especially in the building sector, which accounts for $04 \%$ of energy consumption in the country Has been given attention. (Zarghami, Ismail and Seyedeh Ashraf Sadat, 2014) Sustainability Despite its universal and universal slogans that are global and target the question of conservation, to achieve realistic and applicable solutions on the one hand, and to support the diversity that exists in nature, on the other, approaches It recommends the local area and consider the global motto "Think, but act as an area". 
This approach has a lot to do with the definitions of native architecture and architecture. The architecture of native architecture is based on environmental features to meet the human needs of the environment. This architecture has been influenced by the economic, cultural, social and climatic conditions and is being implemented by local architects to meet the needs of local communities. The cultural, social, and cultural diversity in the climatic zone has a direct impact on the form and technology of native architecture. In general, native architecture embraces the conditions and characteristics of each environment in relation to the natural factors or spiritual desires of humans. All forms of native architecture have been made to meet the specific needs, specific biological qualities, economics and livelihoods of the cultures that created them. (Falamaki, 2005)

One of the main goals of sustainability is the reduction of non-renewable resources and fossil fuels. Optimal use of climate factors in building design is one way to achieve this goal. Centuries ago, in traditional architecture of Iran in different regions, depending on the climate of that area, they built various buildings that would be enjoyable in spring, summer, autumn and winter. In our country, buildings were designed for the optimal use of natural energies. The way buildings were erected based on the direction of wind and sun and ... It was possible to provide heating and cooling without using fossil fuels. (Mousavi, Ali, 2014)

"According to Edward Brian," Traditionally, the traditional architecture of the world is a rich source that has a significant potential to help us understand design and sustainable construction. Indigenous buildings are made available from local materials, local applications, renewable energy sources. " Also, all cultural, social and economic aspects are respected.

Traditional Iranian architecture and urbanization is not only an exception to this rule, but also as one of the most complete forms of context-oriented world. Cities need a favorable natural environment, cultural and social relevance, and economic life to sustain their lives. These cases have been properly intertwined with various environmental conditions in Iran (climate and livelihoods, culture and tradition). Regarding natural factors, traditional Iranian cities have adapted themselves to the environment as if they were the environment. In these cities, it is planned for natural phenomena, whether they are favorable or disadvantaged. Though technical know-how has its own particulars in terms of time, but past urbanism has promising enormous technologies in the desirable use of nature. In traditional urbanization, people have an individual life and a collective life. The social connection in a neighborhoods (neighborhood) is a necessity of life in a traditional Iranian city. The most important factor in this urbanization is the expansion of the social and cultural environment and local relationships. Thus, the economy itself becomes a function of social and cultural conditions. (Shieh 1999: 4)

On the other hand, the rules of native design by Pirnia are referred to as principles that, given the diversity in each region, share common principles. In these principles, all the considerations of climate, human, cultural and ... were considered. The native design includes two general principles of climate and human design. In the design of climate in the native architecture of all the climates of Iran there is a common point and it is inspired by nature. The use of natural plants, natural light, natural ventilation, temperature characteristics, building design, etc. is included in this architecture. The design of the native architecture is the one that is most consistent with the climate, making it the least imposed for the environment.

On the other hand, the most important principle of sustainability common to common native architecture is the human design that addresses the biological capability of all components of the global system. This principle is deeply rooted in the need to preserve the elements of the chain of biological systems that the survival of a human being depends on their existence. The most essential role of architecture is to create created environments that maintain their safety, health, physical comfort, mental health and productivity of their inhabitants. (Mahbani 2009: 20) 
Other principles of native architecture, which are consistent with and consistent with the principles of sustainability, are self-esteem, which means the optimal use of materials in the construction site. Iranian architects were trying to get the necessary building material from the nearest places and were constructed so that they would not need to be constructed elsewhere and would be "self-sufficient". Thus, the work was done more quickly, and the building became more "more resilient" with the nature of its surroundings, and its construction was always available when it was renovated. Iranian architects believed that the construction should be "boom" or "idiary" (here). In other words, the product (product) is the place where the building is built and, as far as possible, use local amenities. (Pirnia 2007: 31) From the point of view of cultural and social dimensions, the principle of introversion and people is one of the principles shaped by the cultural needs of the inhabitants, the importance of the realm and belonging. Avoiding futility is also needed to get the most out of your performance, such as controlling your spending cuts. Neish, the reliability of the building and the Peyman are other principles that have been of great importance in the design of the buildings. Static knowledge, building techniques, materials science, the use of geometric rules, and the understanding of forces in the structure of buildings are characteristic of Iranian native architecture. The use of Peyman enables the architect to create flexible spaces, and this flexibility will lead to an extended life (30)

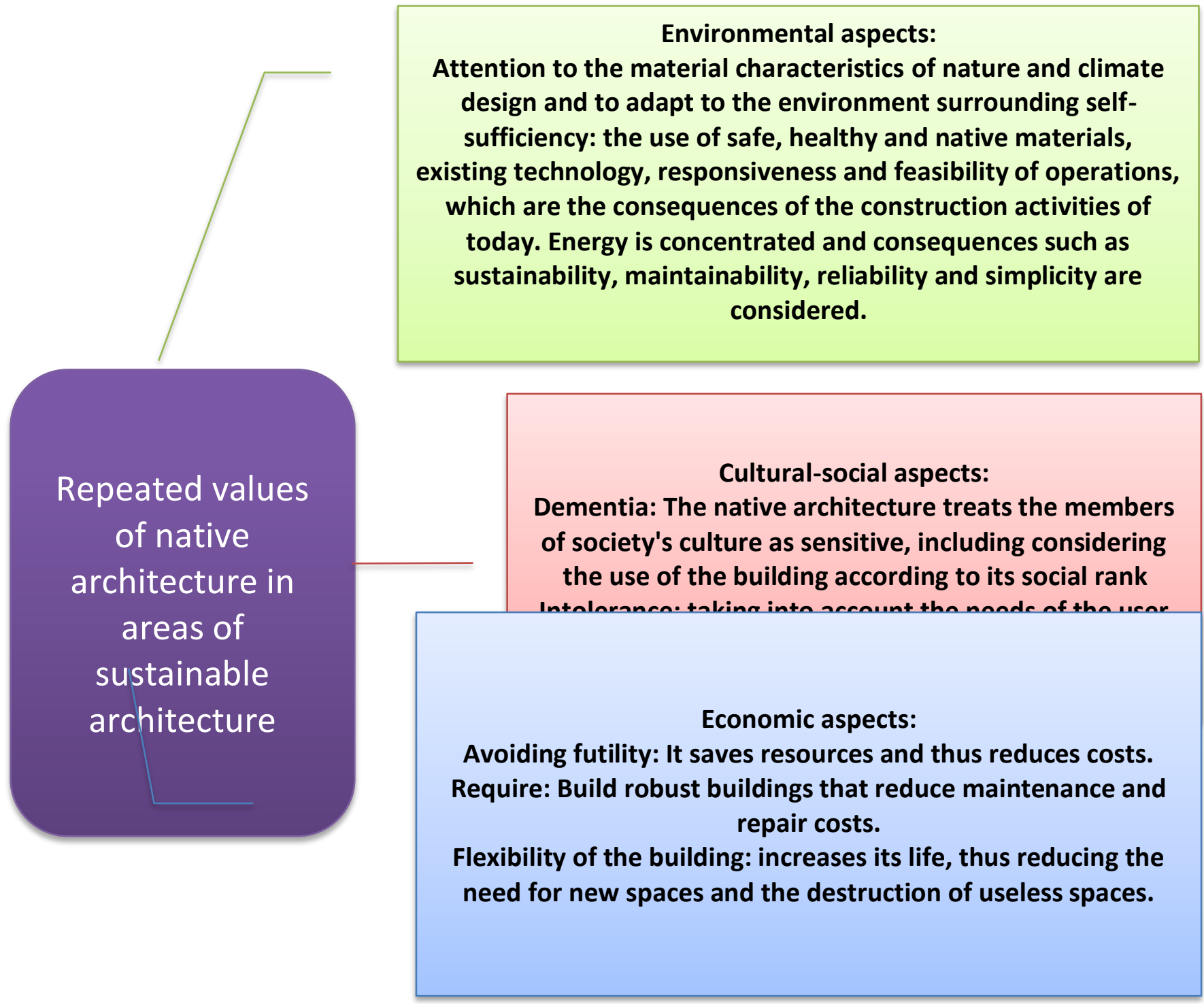

Figure 1 - Repeated values of native architecture in areas of sustainable architecture 
The study of these principles and their analogy with the aspects of sustainable architecture and urbanization is well illustrated by the many values inherent in traditional Iranian architecture. The elements of the Iranian city are comparable to modern cities. The only factor is the differentiation in technical knowledge and the need for time and evolution. This is the result of the social, physical and economic cohesion of the environment that the Iranian city also possesses. Despite such valuable capital, today, the trend towards traditional architecture has been more decorative and less content and functional. Thus, the natural elements in traditional architecture, such as winding, dome, central courtyard, Shawadan, Zohair, canopy, and such that they had a significant environmental performance and greatly reduced the need for the building to conventional fuels, and along with the operation, the creation of nodes Social issues at the level of the building or neighborhood, have been less considered in architecture education. In many developing countries, these trainings have only a descriptive position, and there is less evidence of how to use it and combine it with modern architecture and to obtain some kind of high-performance architecture. (Sada Zarabadi, Khazaei 2007: 8) Meanwhile, modern urbanization and architecture have not only helped to improve the living conditions and the environment, but also in many cases have caused irreparable damage. For example, the results of comparing modern, traditional and industrial architectural and urban planning with the criteria for sustainable design in the neighborhood dimension have been as follows:

Table 1. Comparative Comparison of the Physical and Social Characteristics of the Traditional Neighborhood, Dying, Industrial, and Pattern as Sustainable Neighborhood

\begin{tabular}{|c|c|c|}
\hline Social & Physical & \\
\hline $\begin{array}{l}\text { - Face to face communication } \\
\text { - High social interactions }\end{array}$ & $\begin{array}{l}\text { - small } \\
\text { - Dense texture } \\
\text { - Organic } \\
\text { - Provision of basic needs of residents } \\
\text { - relies on walking } \\
\text { - Definition of specific areas from private } \\
\text { to public }\end{array}$ & $\begin{array}{l}\text { Traditional } \\
\text { neighborhood }\end{array}$ \\
\hline $\begin{array}{l}\text { - Migration of villagers to the city (workers } \\
\text { seeking work ) } \\
\text { - The beginning of severe class separation } \\
\text { and the formation of neighborhoods based } \\
\text { on income levels } \\
\text { - Gradual loss of face-to-face relationships }\end{array}$ & $\begin{array}{l}\text { - The physical formation of } \\
\text { neighborhoods in the vicinity or center of } \\
\text { large and small industries } \\
\text { - Formation of Mahallat's body based on } \\
\text { the dominant role of transportation of } \\
\text { goods and humans } \\
\text { - Severe environmental pollution due to } \\
\text { the presence of industries in industrial } \\
\text { cities } \\
\text { - Gradual separation of man and nature }\end{array}$ & $\begin{array}{l}\text { Industrial } \\
\text { neighborhood }\end{array}$ \\
\hline $\begin{array}{l}\text { The passage from collectivism to } \\
\text { individualism and the isolation of } \\
\text { individuals in the context of society } \\
\text { (individuality and individual orientation in } \\
\text { all basins is evident) }\end{array}$ & $\begin{array}{l}\text { - Vehicle Governance on the District } \\
\text { Automobile } \\
\text { - High-ranking neighborhoods } \\
\text { - Low density in the suburbs } \\
\text { - Neighborhood texture rupture }\end{array}$ & $\begin{array}{r}\text { Modern } \\
\text { neighborhood }\end{array}$ \\
\hline $\begin{array}{l}\text { - Emphasis on local communities } \\
\text { - Emphasis on increasing communication } \\
\text { and interactions in public spaces to } \\
\text { enhance social interactions }\end{array}$ & $\begin{array}{l}\text { - Emphasizing the intensive development } \\
\text { pattern in neighborhoods } \\
\text { - Mix and mix } \\
\text { - Use more efficient than ground } \\
\text { - Expansion of green spaces in the } \\
\text { neighborhood } \\
\text { - Creation of multipurpose centers } \\
\text { - A pedestrian and priority for } \\
\text { pedestrians and bicycles in neighborhoods }\end{array}$ & $\begin{array}{l}\text { Sustainable } \\
\text { neighborhood }\end{array}$ \\
\hline
\end{tabular}

Therefore, it seems that the extraction of the pattern and characteristics of the traditional and native city can play a significant role in achieving the city's design and sustainable architecture.

Native architecture of Kerman and its sustainability 
Kerman is a civilization in the desert. The basis for the formation of the texture and body of Kerman architecture is the climate and its natural bed. Though factors such as culture, social structure, livelihoods, and economics have been involved in its formation. Kerman, located in a warm and dry climate of the country, is one of the most promising cities in the world, whose historic texture, despite the physical damage caused by modernist thinking, has maintained its vitality and vitality through its urban and architectural richness in a climate-friendly manner. Nevertheless, in the process of designing and planning new urban development, the sustainability principles, including climatefriendly design, have been forgotten. In this research, we try to examine the pattern and the characteristics of the historical context of Kerman city, to be used as guidelines for sustainable city design.

Basically, the city of Kerman has been developing in terms of natural conditions, acute geography, both in the winter and in summer, and special geology for nutrition, and has been working hard over the centuries to survive. Perhaps among the desert and desert cities of Iran, the city of Kerman has the most solidarity and humility against nature, especially the violent climate conditions. The city faced with problems such as summer heat, cold winter, high temperature fluctuations, overheating, winds with cold winter burning, and dust and hot summer heat. In other words, the region has a violent and incompatible climate that has never been shown to its inhabitants.

While the traditional architecture of Kerman can be a striking pattern in observing the principles of the new architecture of this ancient city. According to the elderly, this city has suffered from a period of droughts, sandstorms, and periods of colossal winters and snow sinking, according to the elderly. According to climate studies, the intensity of the summer heat sometimes reaches more than 40 degrees Celsius, while cold winter temperatures have reached minus 20 degrees Celsius in some years. The dry, intense summer heat is also heavily burned by winds and sometimes with dust. The existence of narrow and narrow streets protects residents of the city from burning sunlight and dusty effects. Subways over the narrow streets of the city provide more shadows on the street level.

The internal organization of the traditional city includes the public sphere, such as the market, to private, such as the home. Alley through the market opens the way to the neighborhoods, and gradually it is divided into smaller, smaller and more private ways. The market passes through the alley to the door and door to the house. The paths of the tall walls or the exterior of the houses offer a pleasant shadow and provide a great place on the hot summer days. Each of the neighborhoods also has a bazaar with the distance from the main market, which includes the shop, hujra, sara and extras and the bath and mosque. In this way, in every corner of the city's massive and urban neighborhoods, besides day-to-day business and dealing with the material world, there is a room for separation from fuss and concentration and worship and addressing the social life of individuals. (Diba, Sanli, Serge , 2012) These gestures describe the self-esteem of each of the neighborhoods in the whole of the traditional city, and goes so far as to be that at certain times, special neighborhoods preserve their original gate and continue to live completely independently (Ghezelbash, Abolzia, 1985)

According to the above, in general, the system of territory in the traditional neighborhoods can be classified as the territory of a single district, the territory of several residential units (neighborhood complex) and the territory of a building. In the following, the characteristics of sustainable architecture in the traditional city of Kerman are also studied in three dimensions. Neighborhood as the most common realm, which is the place of the most social, economic and cultural interactions of the people, and the set of them creates the city and plays an essential role in shaping the urban context and its image; neighborhoods as a semi-public domain The context of the social and cultural interactions of the inhabitants of several houses is the scale of the building, such as the house, which is a private space, a place of family interactions and has special features to address their needs (Sanei et al, 2017)

\section{Sustainability with emphasis on neighborhood}


With a comprehensive look at the traditional architecture of the city and the Kerman neighborhood, four basic principles are well understood. The specific orientation of textures and passages, texture density, the construction of covered passages and the use of mud and mud are four basic principles in shaping the texture and appearance of Kerman city and neighborhoods. The main contribution of the use of these principles is related to the climatic factors. But a more accurate look, these principles are not only responsive to the biological and climatic needs, but also subtle and artistic backgrounds, citizens' beliefs and social needs. One of the most important issues is urban planning, for the purpose of house and passageways or Rhône. The orientation of the texture and passageways is due to the warm sunshine in the afternoon and warm and stormy winds, in the direction of the northeast to the southwest and perpendicular to it. Hence, the orientation of houses and components will be in the direction of the northeast to the southwest, or, in other words, according to Rhine. This kind of orientation has not only been beneficial in terms of climate, but also the placement of parts to Qibla, both religiously and culturally important.

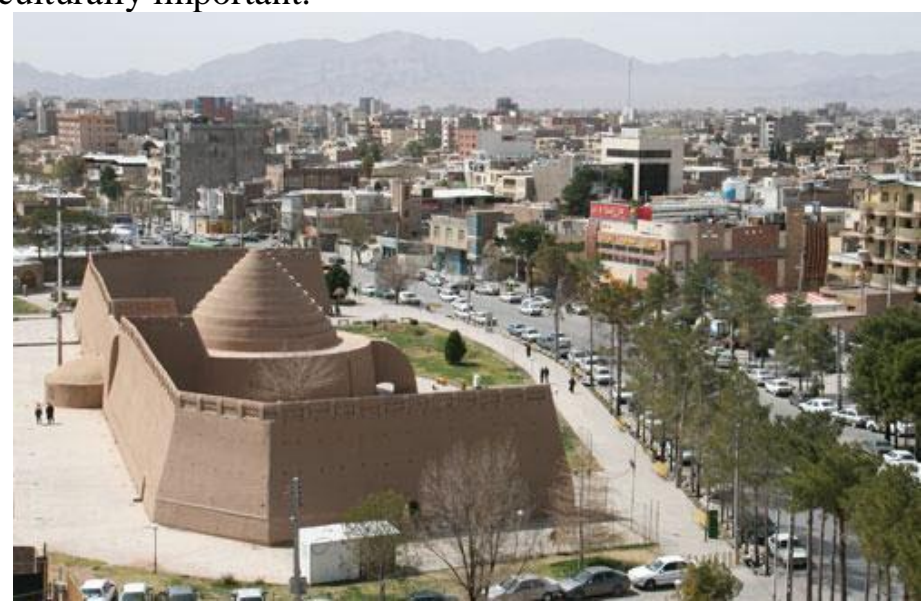

Figure 1 - A glacier of traditional architecture examples

The formation of dense texture in order to prevent the influence of heat and extreme cold of summer and winter and the unconformable winds into the texture, is the second principle regarding sustainability in the central and southern cities of Iran, including the city of Kerman. This way, in most cases, pedestrians will be protected from the warmth of the burning sun with a pleasant shadow. The texture density will slow down the transit paths. But in the streets, despite the tightness, due to the spatial diversity and the lack of uniformity, the feeling of a bitter hardship to humans did not stop. On the other hand, it is more reserved and less aristocratic. The color of the body material enclosing the space also plays a major role. In desert cities, the color of the soil and the dwarf, in spite of the lack of tracks, gives people peace of mind. (Tavassoli, 1989)

Indoor passages on the one hand prevent intrusive winds and, on the other hand, provide the greatest amount of shadow due to their depth. Using this method is the third basic principle in the design of Kerman urban texture, which directs the localities. In the neighborhoods of Kerman, the markets and the entrance of the mosques and baths are built indoors. In this case, the interior is protected from sunlight and inadequate atmospheric conditions and is illuminated by ceiling light. 


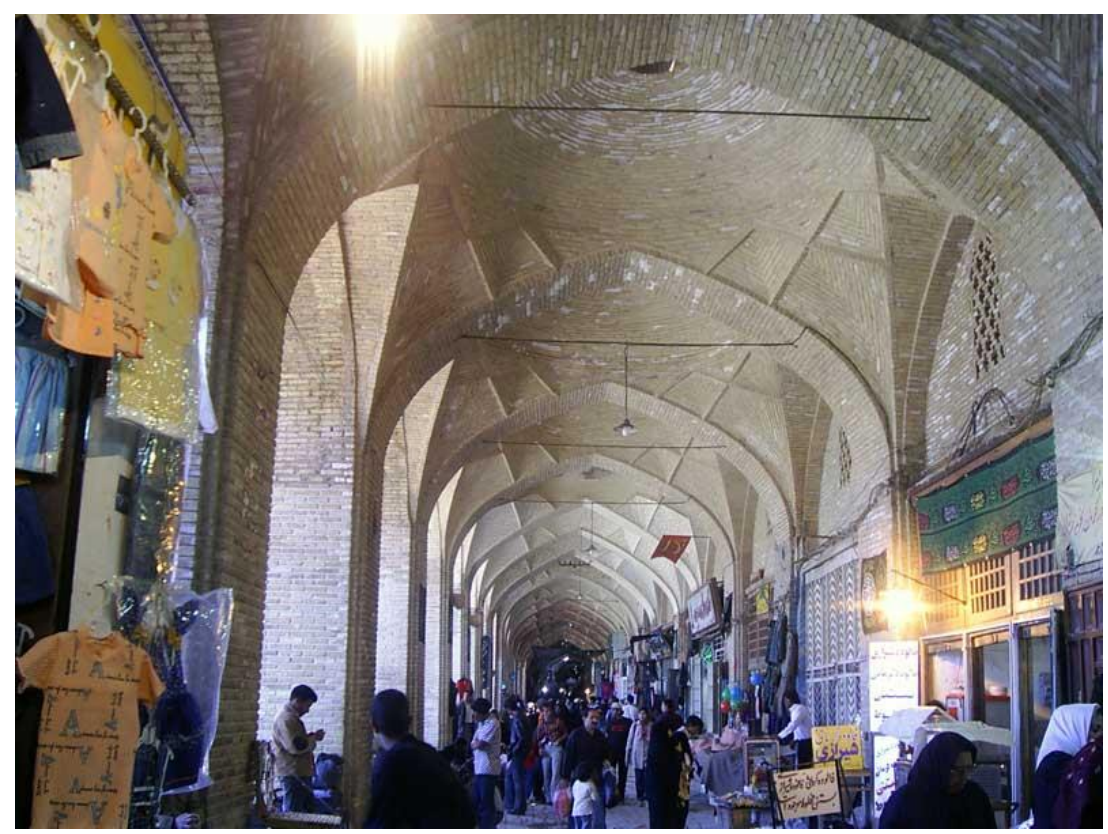

Figure 2 - Kerman Market

Another type of indoor passage has been created by footboards. This name has an ancient root in Persian and Persian, including Persian. The first part of this "sa" means comfort and the second part is the "Bhat" extension of the building, building, and mansion chart, and is used altogether as a sanatorium and recreation center today. (Pirnia, 2004: 231) The purpose of the design and implementation of the subculture is to keep the tattered man underneath his shadow, protecting the sun from radiation. The way to set footboards is such that a walking person places his path in a proper sequence in the shadow space. In many places, the entrance of several houses has been integrated, which is also important for the increasing sense of neighborhood and neighborhood solidarity. It is also possible to say that the pavements were the shadows that were built in front of the entrance so that the guests were protected from the heat of the sun and the heat, and they would not be harmed at the time of the arrival of the owner and opening it up (Pirnia 2005: 159)

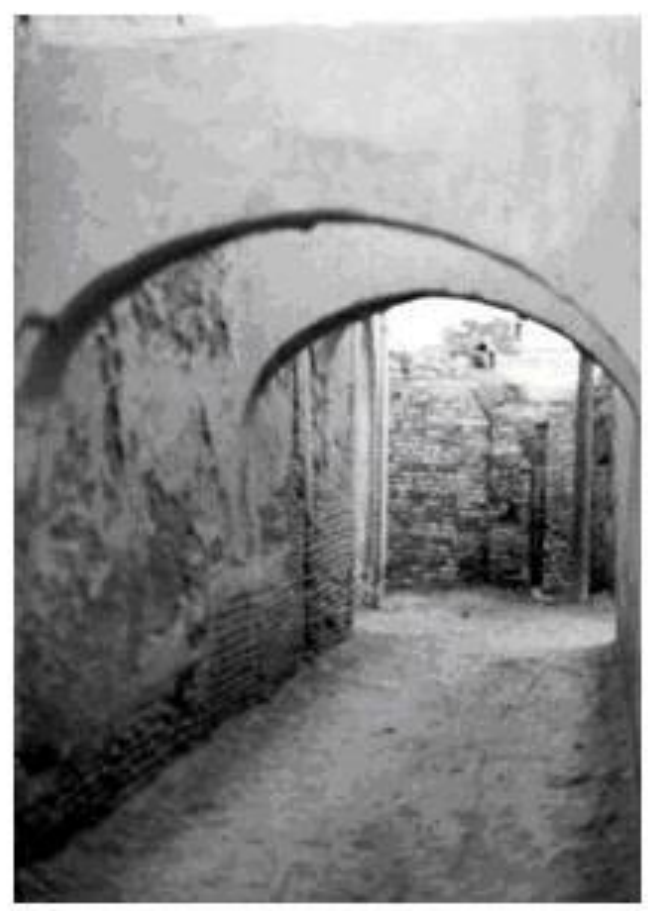

Figure 3 - Pantyhose with two lambs in the ancient clay of Kerman city 
Thus, the indoor passageways, in addition to the positive climatic, environmental and energy effects, have created powerful social nodes at the surface of the road and the surrounding area. Also, in many cases, especially in the passages between the two buildings, slabs were used as structural members to neutralize the load of high walls.

What attracts the viewer in Kerman at first sight is the role of mud and mud everywhere, both inside and outside the houses. Basically, after selecting the location for the building (if it is not located in the hole), the land is excavated to use the soil and materials and to form the basements. The use of mud materials in desert areas, and in particular Kerman, has had climatic, technical and technical reasons. In this area, no other materials under the sun's rays are resistant to heat. In the cold season, it is heated with a little heat, too. (Architects, 1373: 270) On the other hand, these materials heat up late in the day and return to the heat during the night, which modulates the heat fluctuations in the building throughout the day. In the courtyard of traditional houses, which are carpet-tiled, the air temperature is very low on the brickyard surface, and at night, when the air is cooled, these bricks still retain heat, and the yard space does not get cold early. In this way, the use of bulk materials does not only play an essential role in setting environmental conditions, but also in the least possible way. Thus, the costs of transportation of materials from other areas to the site of construction have greatly decreased or even reached zero.

The materials described clearly show that the characteristics of urban texture and traditional neighborhoods are largely consistent with sustainability criteria. The principles used are well suited to the existing climate and improve the living conditions of the inhabitants and citizens in the least possible way, and, on the other hand, the need for fuel and thus the pollution of the environment greatly reduces. On the other hand, these spaces, in a completely organic way and based on the needs of those of those times, could properly serve the needs of the people, as well as the social, economic, and cultural interactions. The interior image of the neighborhood in the old context has a consistent and consistent view, because there is less a house that distinguishes itself from other houses in height or appearance. (Dehghan Nejad, 1997) This affair and neighborhood centers with the inclusion of various elements of the city for the residents of the neighborhood, in addition to emphasizing justice and equality in access to services, create a sense of belonging to the place and social sustainability. With the presence of local people and elders in the center of the neighborhood, the moral frameworks of each neighborhood are formed. Narrow passages emphasize on face-to-face communication and pedestrian superiority.

\section{Sustainability with emphasis on neighboring units}

Traditional neighborhoods are a set of residential units that are organized and grouped around deadlock alleys. Deadlocks as the main element in the context and the network of access to the city and the common space and communication between residential units and neighborhoods were in Iranian cities. The impasse space can be considered as a semi-private arena between neighbors, which has been created with a particular diversity in the context of the city, and each section with its own texture and size has made the city's identity more objective. (Zarghami, 1999) Thus, although the central square was considered as the center of the neighborhood, social activities continued along the alleys. For example, women gathered from neighboring houses and sat on platforms on the podium. It was also part of their daily work, such as knitting and sewing.

Small alleys, especially deadlocks, were used by residents of the neighborhood for all kinds of activities. This reinforced the feeling of privacy and space-based living in the community. So a nonresident was a stranger in the neighborhood, and when he was in the neighborhood, he was quickly identified by the residents of the neighborhood. (Khaksari 1385) Some of the streets were separated from the more general neighborhood by occupants. Darband is an alley and an impasse which connects several independent houses and sometimes has a separate unit that was closed at night. It should be noted that the entrance is short, so that the entrance to this alley should bend the head, due to introversion and on the other hand to the security. (Rohizadeh 1999) 
Neighborhood neighborhoods provide social interactions in the traditional neighborhoods of Kerman. This is very close to sustainability criteria, including the need to increase face-to-face interactions and create community-based social partners at the local level and in the city. Alleyways, penthouses, security guards, and so on, create the right boundary between privacy and publicity, creating a sense of security and, therefore, belonging to existing space. This is also closely aligned with the culture on the bed. Subtabs have created the right nodes for dialogue and social interaction. On the other hand, the existing physical form will be fully responsive to the climate.

\section{Sustainability with an emphasis on traditional buildings}

Each residential unit or service, on its own, has used several principles in its construction. These principles, which are often aligned with the specific climatic conditions and to improve the living conditions of the inhabitants or users, are precisely aligned with the cultural, religious beliefs and existing social structures. Perhaps the most famous feature of the construction of desert towns, including Kerman, is windfall. Buildings that are protected by their central yard orientation and use of unfavorable conditions and adverse weather waves are masterfully used by wind turbines to provide optimal winds to improve the environmental conditions and the proper ventilation of their own air. Combining the use of wind turbines and water ponds to increase moisture has been very effective. On the other hand, the environment created under the wind turbine has become a good point for family gathering. The Kermani windshield, which is simple and almost impregnable, is dedicated to middle and low-class houses. The construction of this kind of wind-up takes care of any building and its major materials are mostly mud and mud. The work of this wind-up is somewhat more accurate and more ideal than windfall of other Iranian desert regions. Because the pressure of the wind in one direction causes rapid depletion of hot and contaminated air on the other side. In addition, winding most of the water storage is also made as a kermnym wind to get from one side of it, the air reaches to the surface of the water and, on the other hand, hot air to go out.

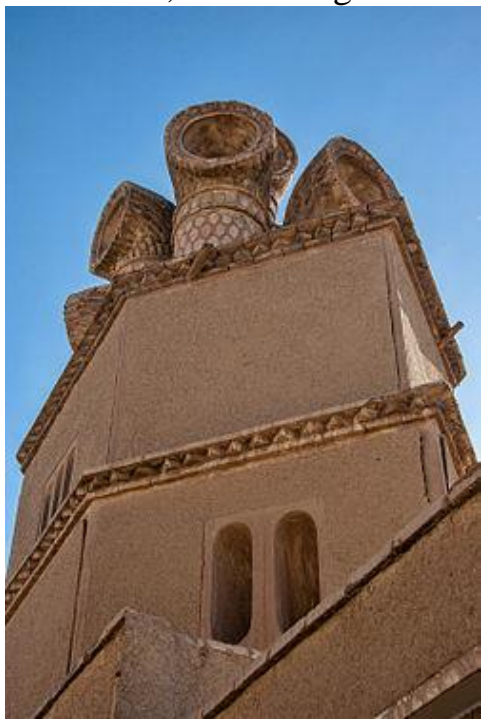

Figure 4 - Sirjan's windproof winding of the unique types of Kermani windmills

Creating the central courtyards in order to provide cool and comfortable air for every residential unit is one of the other principles of making hot and dry climate cities in Iran. The breathing of compact houses is possible from inside the courtyards. The courtyards, like the cooler pit, settle down at night and use the warm day. These gardens, in addition to the air regulating properties, block the wind, create shadows, and keep small living and inner privacy against open and unsafe spaces. In Kerman, the courtyard is an entirely different environment; in this small garden the inhabitants create a pleasant environment by planting beautiful trees and flowers of manes with Kerman nature. (Memarian , 1994: 285) The use of dock and vegetation not only helps the beauty of the interior, but also has a special role in reducing the dry air. The shadow of the trees and surrounding walls is also a good place to bring together family members together. 


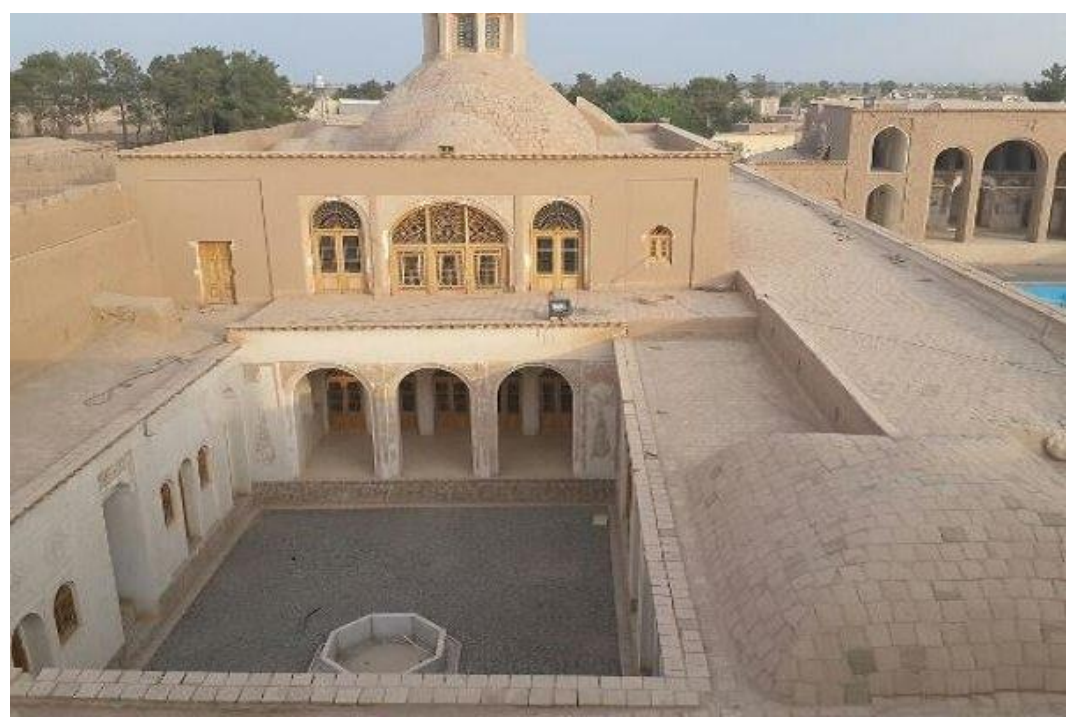

Figure 5 - View of the courtyards of Kermani houses

In addition, the yard is an important element in organizing various spaces in different seasons. In this way, all of their spaces and openings are facing the courtyard, and thus the level of openings on the side of the alleys, to a large extent, is reduced to a large extent in order to lessen the influence of unfavorable conditions. The role of communication and movement of the courtyard is another feature of it (the same)

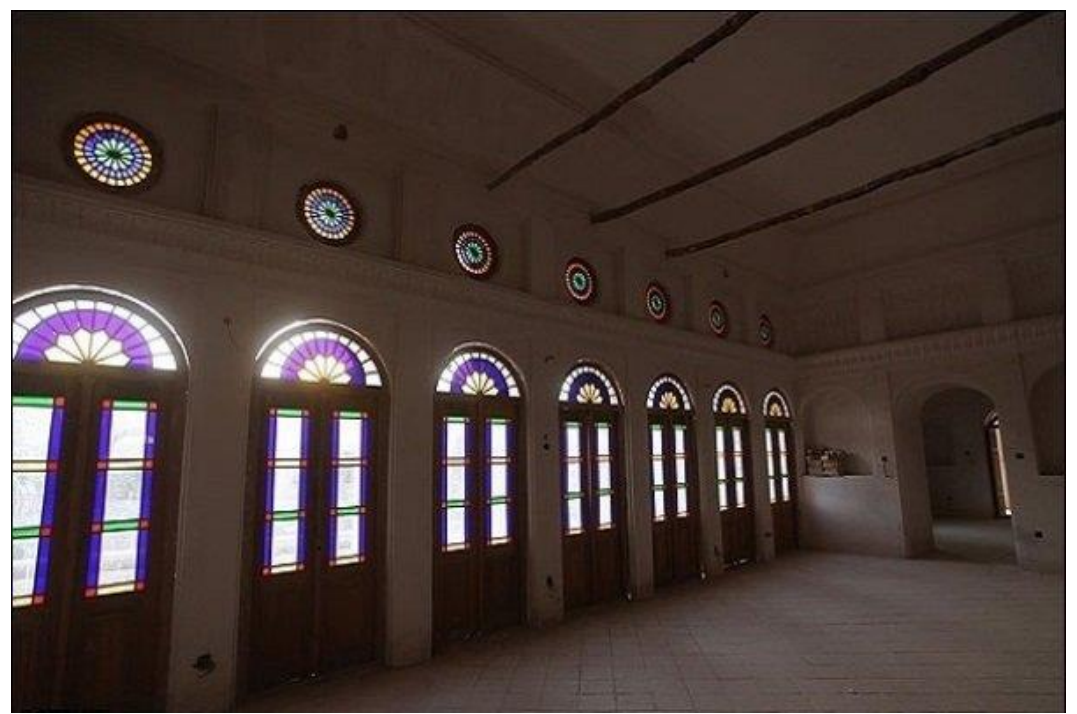

Figure 6 - Interior view of Kermani houses

\section{CONCLUSION}

Considering the issues raised, all the principles and characteristics of urban texture, neighborhoods and buildings of Kerman city are in the same direction in full accordance with the general principles of sustainable architecture and urban development that are expressed in three general environmental, economic and social domains. All of these principles have been applied with the least cost and pollution and no need for energy to improve the environmental and climate conditions. In addition, each has a significant role in creating a platform for social interactions, while at the same time fully aligning with the beliefs and culture that governs its context. This is a proof of continuing the flow of life in the old context of Kerman. The following table briefly describes the elements of the architecture of Kerman city with sustainable urban development criteria. 
The Turkish Online Journal of Design, Art and Communication - TOJDAC

ISSN: 2146-5193, March 2018 Special Edition, p. 300-316

Table 2. Matching the Native Architecture Elements of Kerman with Sustainable Urban Development Criteria

\begin{tabular}{|c|c|c|c|}
\hline Cultural-social & & Environmental & \\
\hline $\begin{array}{l}\text { Creating a sense of } \\
\text { social justice } \\
\text { Beautiful paths }\end{array}$ & $\begin{array}{l}\text { Reduce the cost of } \\
\text { improving } \\
\text { environmental } \\
\text { conditions and } \\
\text { energy } \\
\text { consumption } \\
\text { Reduce } \\
\text { transportation costs } \\
\text { of materials } \\
\text { Reduce shipping } \\
\text { costs to cover } \\
\text { living expenses }\end{array}$ & $\begin{array}{ll}\text { st of } & \begin{array}{l}\text { No environmental } \\
\text { pollution } \\
\text { consistent with }\end{array} \\
\text { and } & \text { the existing } \\
& \text { climate } \\
& \\
\text { costs } & \\
\text { erials } & \\
\text { ping } & \\
\text { cover } & \\
\text { ing }\end{array}$ & $\begin{array}{r}\text { Indigenous } \\
\text { materials }\end{array}$ \\
\hline $\begin{array}{l}\text { Emphasis on increasing } \\
\text { communication and } \\
\text { interactions in public } \\
\text { spaces to enhance social } \\
\text { interactions } \\
\text { Creating a sense of } \\
\text { social justice and } \\
\text { belonging to the } \\
\text { environment } \\
\text { Emphasis on local } \\
\text { communities }\end{array}$ & $\begin{array}{l}\text { Reduce shi } \\
\text { costs to } \\
\text { living expense }\end{array}$ & $\begin{array}{ll}\text { ping } & \text { Improve } \\
\text { cover } & \text { environmental } \\
& \text { conditions and } \\
\text { shade }\end{array}$ & $\begin{array}{r}\text { Indoor } \\
\text { passageways }\end{array}$ \\
\hline $\begin{array}{lr}\text { Face-to-face } & \text { social } \\
\text { interaction } & - \\
\text { emphasis } & \text { on } \\
\text { pedestrians } & \end{array}$ & $\begin{array}{l}\text { Optimal use of the } \\
\text { ground }\end{array}$ & $\begin{array}{l}\text { Shadowing and } \\
\text { improving } \\
\text { environmental } \\
\text { conditions in interacting } \\
\text { with existing climates - } \\
\text { Optimal use of land }\end{array}$ & Dense texture \\
\hline $\begin{array}{l}\text { Creating a good } \\
\text { atmosphere for } \\
\text { meeting members } \\
\text { and } \\
\text { members } \\
\text { Creating } \\
\text { boundary between } \\
\text { private and public } \\
\text { space }\end{array}$ & $\begin{array}{l}\text { Reduce the cost of } \\
\text { improving } \\
\text { environmental } \\
\text { conditions and } \\
\text { energy } \\
\text { consumption }\end{array}$ & $\begin{array}{l}\text { Maintain moisture } \\
\text { Maintaining appropriate } \\
\text { environmental } \\
\text { conditions in the middle } \\
\text { space } \\
\text { Avoid penetration of } \\
\text { unfavorable } \\
\text { environmental } \\
\text { conditions into the } \\
\text { building }\end{array}$ & $\begin{array}{r}\text { Central } \\
\text { courtyard }\end{array}$ \\
\hline $\begin{array}{l}\text { Orientation } \\
\text { towards the Qiblah }\end{array}$ & 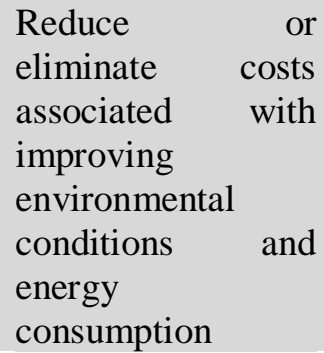 & $\begin{array}{l}\text { To cope with difficult } \\
\text { climates such as } \\
\text { unpleasant winds and } \\
\text { uncontaminated sunlight } \\
\text { without energy } \\
\text { consumption }\end{array}$ & $\begin{array}{r}\text { Texture } \\
\text { orientation }\end{array}$ \\
\hline $\begin{array}{l}\text { Create face-to-face } \\
\text { interactions }\end{array}$ & & $\begin{array}{l}\text { Create thermal comfort } \\
\text { for passages }\end{array}$ & shelter \\
\hline Create face-to-face & & Create comfort for & Alleys, \\
\hline
\end{tabular}




\begin{tabular}{|c|c|c|c|}
\hline \multirow[b]{2}{*}{$\begin{array}{l}\text { interactions } \\
\text { The boundary } \\
\text { between public and } \\
\text { private spaces } \\
\text { Emphasis on local } \\
\text { communities }\end{array}$} & & passersby, residents and & ends, \\
\hline & & guests without energy & $\begin{array}{r}\text { Darband and } \\
\text { Hashti }\end{array}$ \\
\hline $\begin{array}{l}\text { Creating a good } \\
\text { atmosphere for } \\
\text { meeting members } \\
\text { and ramily } \\
\text { members }\end{array}$ & $\begin{array}{l}\text { Reduce the cost of } \\
\text { improving } \\
\text { environmental } \\
\text { conditions and } \\
\text { energy } \\
\text { consumption }\end{array}$ & $\begin{array}{l}\text { Ventilation and cooling } \\
\text { of space without energy } \\
\text { consumption } \\
\text { contamination }\end{array}$ & Windproof \\
\hline
\end{tabular}

The architects of the native village buildings have not been owners of houses that have identified features of the useful and harmful areas of the region, such as materials and weather, to prevent harmful factors and take advantage of beneficial factors. Sustainable architecture approach requires proper native bodybuilding, but traditional policies that have led to shelter shelters that have been stable for centuries are not meeting today's needs and resources, so here are the meanings Due to the native features, attention is paid to its values. Paying attention to the native features is remarkable in two directions: one, creating a suitable platform for the formation of sustainable architecture, and the other, using the native architecture's repeatable values in the architecture process.

While traditional architecture treats the best, cheapest, and cleanest possible interaction with nature, today, new structures continue to operate without regard to these precious treasures and impose huge economic, social and environmental costs. It seems that looking at this valuable legacy and applying their principles (not just imitation) in today's architecture and urbanization can help resolve many of the problems that have arisen.

\section{REFERENCES}

Adams, w.m(1999); Green development Report, oxford university press, New Yourk. Armaghan, Maryam and Gorji Mahlbani, Yousef, 2009, Iranian Native Architecture Values in Relation to Sustainable Architecture Approach, Housing Quarterly and the Village Environment, No. 126.

Bahreini, Seyyed Hossein, Maknoon, Reza, 2001, Paper on sustainable urban development from thought to action, Journal of Environmental Studies, No. 27, p. 60-41.

Barton, Thomas(etal) our Resources. Gland, Switzerland and Cambridge, UK; IUCN, the world conservation union 1997.

Dehghannejad, Fatemeh, 1997, Ancient Texture of the World, Isfahan, Isfahan Cultural and Recreational Organization.

Diba, Darab and Philip, Rival and Sanli, Sergeh, 2012, Houses of Isfahan, (Maryam Ghasemi Sayani), Isfahan, Islamic Azad University, Khorasgan Branch.

Edward, Brian, translated by Shahrooz Taharan 2010, Guidelines for Sustainable Architecture, Tehran, Second Edition, Publishing Mehrazan.

Falamaki, Mohammad Mansoor and Alpa Gonvolo, Adriano and others, 2005, Native architecture, Tehran, Second Edition, Cultural Space Research Institute.

Ghezelbash, Mohammad Reza and Abolzia, Mohammad, 1985, The traditional alphabet, Tehran, Ministry of Planning and Budget.

Haughton, G(1997);Developing sustainable urban development models, cities 14.

Khaksari, Ali and Shakibamanesh, Amir and Ghorbanian, Mahshid, 2006, Urban neighborhoods in Iran, Tehran, Institute of Humanities and Cultural Studies

Mahmoudi, Mohammad Mehdi, 2009, Development of Sustainable Housing with Sustainable Development, Tehran, Tehran University Press. 
Memarian, Gholam Hossein, 1994, Introduction to Iranian Residential Architecture. Tehran University of Science and Technology.

Mousa Kazemi Mohammadi, Seyyed Mehdi, 2001, Sustainable Urban Development, Concepts and Views, Geographical Quarterly, No. 62.

Mousavi, Ali, 1994, Sustainability in Iranian traditional and traditional architecture (Case study: Boroujerdi's House), National Conference on Architecture and Sustainable Urban Landscape, Mashhad, International Institute of Architectural and Urban Studies, Mehraz City.

Nasiri, Hossein, Sustainable Development of Third World Outlook, Culture and Andesh Publications, 2000.

Pirnia, Mohammad Karim, 2005, Introduction to Islamic Architecture of Iran, Iran University of Science and Technology.

Pirnia, Mohammad Karim, 2008, Stylistics of Iranian Architecture, Editor: Architects, Alem Hussein, Tehran, Soroush Danesh.

Ray,sunil(1993), "sustainable Development through the Development of the Non-form sector",September

Roohizadeh, Amir Reza and Seyyed Mehdi, Mirdanov, 1999, The History of the Architecture of Iran and Islamic Countries, Tehran, Ukrash Publications.

Sadeh Zarabadi, Zahra Sadat, Khazaie, Fatemeh, Sustainability of the Neighborhood to the Sustainable Neighborhood, Building and Computer Monthly, Third Year, No. 18.

Sanei, Mohsen, Mina Khodadad, and Farid Panahi Ghadim. "Effective Instructions in Design Process of Urban Public Spaces to Promote Sustainable Development." World Journal of Engineering and Technology 5.02 (2017): 241.

Saux, Iniasi, 1993, Transition Strategies in the Twentieth Century, Nature and Resources, Year 1, No. 3

Saux, Iniasi, 2002, Urban land use planning, Yazd, Yazd University.

Tavasoli, Mahmoud, 1987, Principles and Methods of Urban Design and Residential Spaces in Iran, Center for Urban \& Architecture Studies and Research, Ministry of Housing and Urban Development.

Tousan,cevat(2001); Challenges of sustainable Tourism Development in Developing world;The case of Turkey,journal of Tourist management 22.

Wheeler, Andrea. "Outsider ethics and marginalized aesthetics: The value of contemporary environmental philosophies for designing sustainable architecture." (2017).

Willis,Michael.sustainability:The issue of our age, and a concern for local government.Public P812,MIT press.ISBN,2006.

Zamankhani, Jalal Salek. "Perspectives of Architects on Obstacles of Sustainable Architecture in Metropolitan Areas of Iran." European Journal of Sustainable Development 7.1 (2018): 279-286.

Zarghami, Esmaeil and Seyyedeh Ashraf Sadat, 2014, Investigating the Relationship between the Design of the Architecture of Iran's Traditional Houses and Their Sustainability Components. Case Study: Boroujerdi House, First National Conference on Urban Development, Urban Management and Sustainable Development, Tehran, Iran Institute of Architecture, Iran.

Zarghami, Esmaeil, 2008, Principles of Social Sustainability in Residential Complexes, Tehran, Ph.D., Architectural Engineering, Faculty of Architecture, University of Science and Technology.

Ziyari, Keramatollah, 1999, Planning of New Towns, Tehran, Pos 